\title{
Attending Professional Covert Violence Against Women in Medical Care
}

Asistencia a la violencia profesional encubierta contra las mujeres en la atención médica

\author{
Roberto Rodríguez Gaona ${ }^{1}$ \\ Received: 04/02/2019, Accepted: 18/06/2019, Published: 05/07/2019
}

\begin{abstract}
:
This paper proposes a new category of violence against women in the context of medical care: professional covert violence. A form of violence that normally goes unnoticed and rarely documented. The paper suggests two paradigms about this violence, as well as the mechanisms to prevent it. Identifying and acknowledging this type of violence is especially important for the constant improvement of medical care.
\end{abstract}

Keywords:

Violence against women, medical care

\section{Resumen:}

El siguiente artículo presenta una nueva categoría de violencia contra las mujeres en el contexto de la atención médica: la violencia profesional encubierta. Una forma de violencia que normalmente pasa desapercibida y raramente documentada. Este artículo sugiere dos paradigmas sobre esta violencia, así como los mecanismos para prevenirla. Identificar y reconocer este tipo de violencia es especialmente importante para la mejora constante de la atención médica.

\section{Palabras Clave:}

Violencia contra las mujeres, asistencia médica

\section{Introduction}

When it comes to violence against women it seems that their different types have been sufficiently identified*. The Declaration on the Elimination of Violence Against Women by the United Nations General Assembly (1993) defines it as "any act of gender-based violence that results in, or is likely to result in, physical, sexual or psychological harm or suffering to women, including threats of such

\footnotetext{
* According to World Health Organization violence against women occurs in all countries of the world and takes many forms such as intimate partner violence, sexual violence, honour killings, forced and early marriages, female genital mutilation and trafficking. https://www.who.int

† For example, UN Convention on the Elimination of All Forms of Discrimination against Women and The Council of Europe Convention on preventing and
}

acts, coercion or arbitrary deprivations of liberty, whether occurring in public or private life". There are also international ${ }^{\dagger}$ and specific ${ }^{\ddagger}$ norms to address violence in the sanitary and clinical environment. However, in contemporary societies a Model of Gender Inequality§ still predominates, and that model also has an impact among the professional practice.

combating violence against women and domestic violence.

₹ Mexico NOM-046-SSA2-2005. Domestic and Sexual Violence against Women.

$\S$ Achieve Gender Equality and empower all women and girls is the sustainable development goal number five. Vid. Sustainable Developments Goals. https://www.un.org/sustainabledevelopment/sustainab le-development-goals/ 
Human beings, despite the professional studies they may have obtained, cannot live apart from the Model of Gender Inequality. This model supports social practices and directs behavior.

The Model of Gender Inequality generates diverse forms of violence against people, especially against girls and women*. The Model of Gender Inequality treats women and men differently. Men have the control and attributes that are historically best valued by societies. On the other hand, women appear most of the time in a secondary role or with less amount of social representation that are valuable or important to society.

In this sense, this model ends up influencing all aspects of life in a society such as: laws, religion, coexistence behavior, and roles in the public and private context. However, the impact that the Model of Gender Inequality has on the daily practice of the professions is rarely considered. Specifically, in the field of medical care ${ }^{\dagger}$.

There is a form of violence against women that has a masked, silent and hidden form, justified based on the authority that a professional practitioner has. We call it professional covert violence against women. Naturally, this form of violence has its origin in the Model of Gender Inequality. In other words, it is a cultural violence created and justified by society. This allows us to differentiate professional covert violence from other types of violence against women, including the ones that come from mentally ill people. Concrete forms of violence against women have also been documented in certain medical practices such as obstetric violence ${ }^{\ddagger}$.

However, I consider it is necessary to propose the use of the term professional covert violence against women, in order to understand its different expressions in medical care. In this context, the already identified obstetric

\footnotetext{
* According to World Health Organization (WHO), intimate partner violence and non-partner sexual violence are global and regional prevalent. Vid. Global and Regional Estimates of Violence against Women. Prevalence and health effects of intimate partner violence and non-partner sexual violence, 2013.

WHO, Expert meeting on health-sector responses to violence against Women, 2009.
}

violence would be part of professional covert violence, but not the only one of them.

Professional covert violence is a cultural form of violence that is carried out in a hidden way against the identity and the body of women, justified in the authority of the medical staff and disguised in authorized medical procedures, or in the simulation of authorized medical procedures.

Professional covert violence is an institutionalized violence. It is executed against women, causing damage to their identity and body from a previous conception of the value and relevance of women. It is not explicit and initially goes unnoticed by women patients.

It is important to emphasize that professional covert violence has nothing to do with poor professional competences. Neither is the result of flawed procedures or negligence in medical care. Professional covert violence is the result of the Model of Gender Inequality that stigmatizes and degrades the identity and body of women. It is a violation of women's human rights.

The Model of Gender Inequality represents women in at least three ways:

- As human beings lacking authority over their own bodies and without capacity to decide for themselves.

- As sexual objects for the pleasure of men.

- As inferior beings who deserve rejection or contempt, even hate.

In the social sciences studies, each of the previously mentioned representations can match with the concepts of sexism and misogyny.

That means, the woman is closely related to the attributes that generate or justify violence, only that all these are executed in the medical care. Professional covert violence is related to the general violence that women suffer in a certain society. In other words, professional

WHO, Health care for women subjected to intimate partner violence or sexual violence. A clinical handbook-Field testing version, 2014.

t Of course, violence against health workers does exist. WHO has a Framework guideline for addressing workplace violence in the health sector.

$\ddagger$ Vid. WHO Statement. The prevention and elimination of disrespect and abuse during facility-based childbirth. 
covert violence will be more severe in countries or societies where violence against women is more widespread.

\section{Types of professional covert violence}

The professional covert violence is classified into two types:

1. Direct professional covert violence.

2. Indirect professional covert violence

\section{Direct professional covert violence}

The direct professional covert violence is executed by medical staff (doctors, medical practitioners, and other health care providers) without the intervention of a medical procedure.

It can be said that this type of violence intends to justify the actions based on the credentials or the authority of the medical staff. However, it is not the product of these credentials, but it is the result of masked forms of violation of women's human rights. Particularly, the violation of the human rights to be informed and to give consent in any medical procedure.

This type of violence is manifested by behaviours that conceive a female patient as a lower being that lacks authority, which make her an object or a despicable being. These are some of the concrete behaviours that can be identified:

- Disregard of the patient's opinion concerning her symptoms.

- Negative comments that trivialize the condition or symptoms of the patient.

- Disqualify of the intensity or severity of a pain or discomfort.

- Touch rudely the body of the woman.

- Insinuate that the illness, disease or symptoms are solely patient's responsibility.

- Blame the woman patient for what has happened to her.
- Insinuate that a severe condition or disease causes greater discomfort when is connected with the fact of being a woman.

- Disdain to the organic functions of women, including menstruation.

- Assume that the expressed pain or complaints regarding the side effects of a treatment are related to characteristics that supposedly possess the behavior or mood of the woman.

- Ask about her romantic life or the existence of a romantic relationship.

- Use the masculine "authority" of a father, husband or of a couple to generate feelings of guilt about her illness.

- Eroticize the patient's body. This includes touching the body erotically or in order to inadvertently obtain pleasure from the woman patient.

- Touch the body or parts of the body of the woman patient without any preventive or therapeutic justification.

- Denigrate the body of the woman patient because it is not attractive and based on that pay little attention to the health of the woman.

- Force a woman patient to execute or go under treatments that she does not want despite the existence of other options.

- Do not inform the characteristics of a treatment and disregard any question.

Each one of the conducts represents an act of discrimination and violence that, because is being covert, go unnoticed by the agenda of violations of women's human rights.

\section{Indirect professional covert violence}


The indirect professional covert violence is the one that is executed in different medical procedures*. They are not the procedures per se, but the way in which they are executed or performing according to the idea of women from the Model of Gender Inequality. The woman is a patient who, once again, appears stripped of all authority and value.

It is worth to mention that this form of violence does not intend to do physical harm or an intentional injury to the woman by the medical staff. Nor is it about ignorance of the procedures. If that was the case, we would be facing a case of medical negligence and not covert violence.

In the indirect professional covert violence, we are facing the use of medical procedures that represent violence against women, within the margins tolerated by the same procedures.

Among those concrete behaviours one can find:

- Maximize the pain of a woman in the execution of medical procedures. This includes deliberately delaying the administration of analgesics and anesthetics.

- Execution of procedures that turn out to be easier or more profitable economically, even though the woman does not require them or has not been correctly informed, for example, the performance of a cesarean.

- Manipulate the woman's body without causing injury but pain that is unnecessary during a medical procedure.

- Execution of non-consented procedures in the woman's body, for example, the tubal ligation.

- Causing unnecessary annoyance to the woman, for example, leaving the woman in a certain position without receiving any instruction despite the fact that it is no longer necessary to maintain that same position when the necessary technique has been executed.

\footnotetext{
* Such as propaedeutic, diagnostic, therapeutic, surgical, anaesthesia, screening medical procedures.

$\dagger$ Of course, there is an ethical debate. Understanding a feminist ethics approach is necessary. Vid. Bell, L. A.,
}

- Extending the discomfort caused by therapeutic or surgical procedures beyond what is necessary and even though it does not endanger the woman's health.

- Generate anguish and concern in a deliberate way in the execution of some medical procedures.

This form of covert violence is rarely considered in the improvement of the procedures of any medical institution. Its subtle and covert nature is way to silently violate a woman's body. This type of violence generates fear in many women when thinking about going into a medical procedure, which in the culture of the Model of Gender Inequality is justified from a supposed weakness of women. This idea unfairly conceals a conception of the woman's body as inferior or prone to suffer against any intervention ${ }^{\dagger}$.

\section{Basic tools for preventing professional covert violence}

The goal of any tool must be the nonviolent attention of women through the elimination of any biases that the culture has implanted and that are reflected in professional covert violence.

By virtue of the characteristics of this type of violence, I would like to propose that a procedure needs to be established, including at least 4 stages based on the selfmanagement and self-control of the medical staff, as well as the supervision from the institutions in which they work. The 4 stages are:

1. Visibility and awareness towards the professional covert violence.

2. Application of a check list based on two indexes.

3. Evaluation from the institution about the procedures performed by their medical staff.

Rethinking Ethics in the Midst of Violence. A feminist approach to freedom, Rodman \& Littleield Publishers, Inc., 1993. 
4. Validation of non-violent care or; if it is necessary, report it.

The first two stages belong to the self-control of the medical staff and the last two belong to the controls that the institutions or even the state authorities must execute.

1. Visibility and awareness towards the professional covert violence.

This stage is informative. It mentions that in the procedures and rules of the health centers it is necessary to include a category for professional covert violence. In addition, a gender equality model must be considered.

2. Application of a check list based on two indexes.

I propose to consider two indexes that allow the progressive measurement of the behavior of the medical staff:

- Index of appropriation of the female body

- Index of validation or acceptance of violence by society

The index of appropriation of the female body allows the medical staff to practice a periodic self-control reflection of their behavior. The index refers that during the intervention of the medical staff they have to avoid considering the female body as if it was an object or an inanimate being. Therefore, the behavior of the medical staff must compare how much their practices approach a complete consideration of the woman's body or, on the contrary, if that disposition does not occur.

The expected behaviors when executing the measurement of the index of appropriation of the female body; regardless of lack of training, are the ones most closely related to an informed consent and a proper attention in which the patient is treated and considered with full authority to decide and freely establish their expressions regarding their health care needs.
The index of validation or acceptance of violence by society allows an additional check mark to the behaviors previously evaluated by the index of appropriation of the female body Precisely, one of the main obstacles in the initial evaluation of a behavior has to do with the possible cultural bias from the medical staff related to the fact that there are behaviors that are accepted by society as valid or common ways of treating a woman. Societies justify violence against women, for example, from the idea that they are weak or that they need to suffer violence to guarantee a supposed obedience or conformity with the rules of that same society.

The medical staff uses the index of validation or acceptance of violence by society to confirm if they are not trying to justify a behavior that might be violent but often minimized, based on the cultural context. This allows the medical staff to guarantee that their behavior is not violent.

This may require the participation of an ethical committee to verify that conduct that has caused some trouble is not justified under a violent cultural context.

3. Evaluation from the institution about the procedures performed by their medical staff.

Periodically, a questionnaire should be run to evaluate the medical staff. This questionnaire should include questions that contain the descriptions of the two forms of professional covert violence.

In addition, a random review should be made based on a reasonable sample of the clinical files to verify that any of the parameters of the professional covert violence have not been executed.

4. Validation of non-violent care or; if it is necessary, report it.

The result of the questionnaires and the analysis of the clinical files will allow to validate and determine the quality of the non-violent care of the medical staff and the medical procedures. This means quality assurance according to human rights legal basis for all patients. 
It also allows the identification of recurrent behavior patterns in some members of the medical staff that are an expression of professional covert violence. If this happens, effective measures need to be taken, including a criminal law suit in case that a crime is being committed ${ }^{*}$.

\section{REFERENCES}

1. https://www.who.int

2. UN Convention on the Elimination of All Forms of Discrimination against Women.

3. The Council of Europe Convention on preventing and combating violence against women and domestic violence.

4. Mexico NOM-046-SSA2-2005. Domestic and Sexual Violence against Women.

5. https://www.un.org/sustainabledevelopment/sustainable-developmentgoals/

6. World Health Organization (WHO), Global and Regional Estimates of Violence against Women. Prevalence and health effects of intimate partner violence and non-partner sexual violence, 2013.

7. World Health Organization (WHO), Expert meeting on health-sector responses to violence against Women, 2009.

8. World Health Organization (WHO), Health care for women subjected to intimate partner violence or sexual violence. A clinical handbook-Field testing version, 2014

9. World Health Organization (WHO), WHO Statement. The prevention and elimination of disrespect and abuse during facility-based childbirth.

10. Bell, L. A., Rethinking Ethics in the Midst of Violence. A feminist approach to freedom, Rodman \& Littleield Publishers, Inc., 1993.

* In Mexico discrimination is considered a crime. 